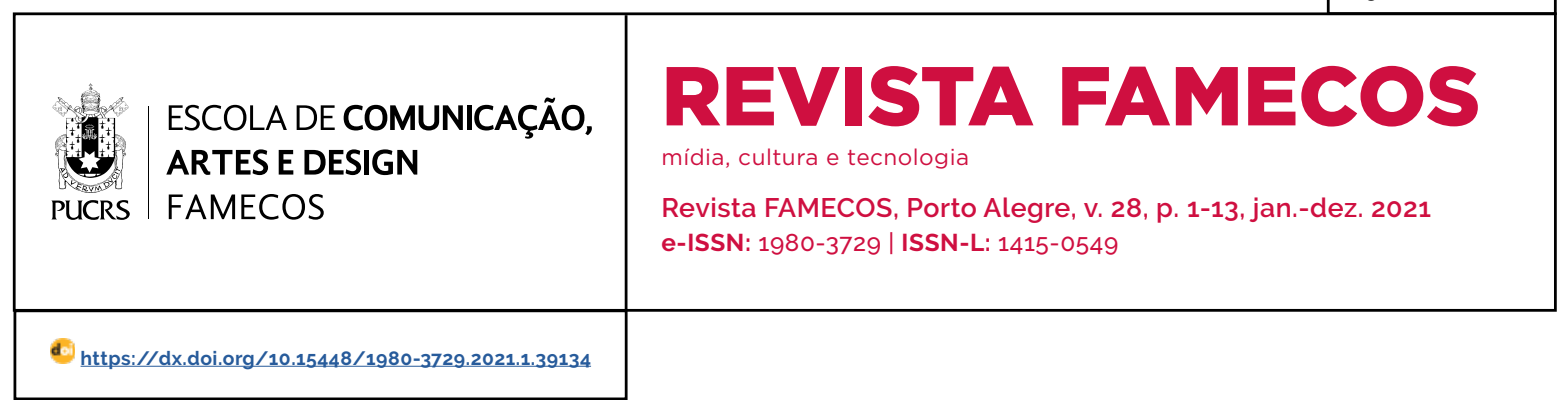

JORNALISMO

\title{
Negociações semânticas na conformação de discursos sobre diversidade e diferença no jornalismo brasileiro de referência ${ }^{1}$
}

\author{
Semantic negotiations in shaping of discourses about diversity and difference in \\ Brazilian reference journalism \\ Negociaciones semánticas en la conformación de discursos sobre diversidad y \\ diferencia en el periodismo de referencia brasileño
}

\section{Nara Lya Cabral Scabin² orcid.org/0000-0002-7121-1142 naralyacabral@yahoo.com.br}

Recebido em: 14 set. 2020 Aprovado em: 1 jun. 2021. Publicado em: 20 ago. 2021.
Resumo: O artigo propõe a análise do discurso de reportagens que visibilizam minorias de gênero e sexuais publicadas em três jornais de referência brasileiros (O Estado de S. Paulo, O Globo e Folha de S.Paulo) entre 1978 e 2018. A pesquisa busca identificar regularidades e deslocamentos semânticos em diferentes planos discursivos a fim de compreender como o campo jornalístico responde a tensionamentos enunciativos decorrentes de rearticulações amplas no universo discursivo. Como principais resultados, o trabalho discute a conformação de um discurso jornalístico articulado em torno de um princípio semântico da "diferença" na década de 2010 e sugere possibilidades metodológicas ao estudo de processos de gênese discursiva no campo do jornalismo.

Palavras-chave: Diversidade. Diferença. Jornalismo de referência. Semântica global. Análise do discurso.

Abstract: This paper proposes the analysis of discourse of reports which give visibility to gender and sexual minorities in three leading Brazilian newspapers (O Estado de S. Paulo, O Globo and Folha de S.Paulo) between 1978 and 2018. The research intends to identify semantic regularities and shifts in different discursive planes in order to understand how the journalistic field responds to enunciative challenges arising from wide rearticulations in discursive universe. As main results, the article discusses the conformation of a journalistic discourse articulated around a semantic principle of "difference" during the 2010's and suggests methodological paths to study processes of discursive genesis in journalism field. Keywords: Diversity. Difference. Journalism. Global semantic. Discourse analysis.

Resumen: Este artículo propone el análisis del discurso de reportajes que dan visibilidad a las minorias sexuales y de género en tres importantes periódicos brasileños (O Estado de S. Paulo, O Globo y Folha de S.Paulo) entre 1978 y 2018. La investigación busca identificar semánticas regularidades y desplazamientos en diferentes planos discursivos para comprender cómo el campo periodístico responde a los desafios enunciativos que surgen de amplias rearticulaciones en el universo discursivo. Como principales resultados, el artículo discute la conformación de un discurso periodistico articulado en torno a un principio semántico de "diferencia" durante la década de 2010 y sugiere caminos metodológicos para estudiar procesos de génesis discursiva en el campo del periodismo.

Palabras-clave: Diversidad. Diferencia. Periodismo de referencia. Semántica global. Análisis del discurso.

\footnotetext{
Trabalho realizado com apoio da Coordenação de Aperfeiçoamento de Pessoal de Nivel Superior - Brasil (CAPES) - Código de Financiamento 001.

Universidade Anhembi Morumbi (Anhembi), São Paulo, SP, Brasil.
} 


\section{Introdução}

Em Gênese dos discursos, o linguista francês Dominique Maingueneau desenvolve uma proposta de análise discursiva baseada na definição de "operadores de individuação" (2008, p. 48): critérios que permitam distinguir certos textos como pertencendo a um determinado discurso - e não a outros quaisquer. Isso porque são justamente esses operadores que determinam o dizivel de um campo discursivo ${ }^{3}$ por meio de sua incidência simultânea sobre universos intertextuais - espaços próprios de cada discurso em que se estabelecem relações, circulam actantes, apresentam-se textos e narrativas - e dispositivos retóricos disponiveis para a enunciação no âmbito de um discurso dado.

Segundo Maingueneau (2008), o modo como um discurso mobiliza esses dois domínios é regido por um sistema de restrições único entendido como uma competência discursiva, que não deve ser entendida como meramente linguistica ou gramatical. Disso decorre que o exame da enunciabilidade de um discurso - o fato de ser objeto de atos de enunciação produzidos por um conjunto de individuos historicamente situados requer a compreensão de sua semântica global por meio do exame integrado de todos os seus planos, procedimento que deve revelar as restrições da formação discursiva à qual se vincula. ${ }^{4}$

Se ojogo das restrições que definem a "lingua", a de Saussure e dos linguistas, supõe que não se pode dizer tudo, o discurso, em outro nivel, supõe que, no interior de um idioma particular, para uma sociedade, para um lugar, um momento definidos, só uma parte do dizivel é acessivel, que esse dizivel constitui um sistema e delimita uma identidade (MAINGUENEAU, 2008, p. 16).

Partindo de aportes teóricos da análise do discurso francesa, este artigo investiga os processos de constituição de enunciados que visibilizam minorias sexuais e de gênero no chamado "jornalismo de referência"5 ao longo das quatro décadas compreendidas entre 1978 e 2018. ${ }^{6}$ Elegemos, como foco de atenção, matérias publicadas por três dos principais veículos da imprensa de referência brasileira: O Estado de S. Paulo, O Globo e Folha de S.Paulo. ${ }^{7}$ Antes de prosseguir, porém, é preciso reconhecer o caráter problemático e disputado tanto do conceito de "minoria" quanto da delimitação do que seriam "minorias sexuais e de gênero"; por essa razão, tais noções não serão tomadas aqui como categorias analiticas, mas sim, como categorias nativas, isto é, categorias que emergem do cotidiano social, com origem e significado histórico, conforme a diferenciação dos tipos de conceito nas ciências sociais.

Diante disso, a pesquisa focaliza matérias jornalisticas que abordam aspectos relacionados a vivências de mulheres e pessoas LGBT. ${ }^{8}$ Para tanto, a construção do corpus analítico baseou-se no rastreamento de textos (reportagens e suplementos especiais, cada um considerado como uma unidade de análise individual) relacionados a quatro eixos temáticos capazes de abarcar certa diversidade de temas relacionados às identidades em foco: Dia Internacional da Mulher; (eixo 1) Parada do Orgulho LGBT de São Paulo (eixo 2); Dia Internacional do Orgulho LGBT (eixo 3);

\footnotetext{
3 Referimo-nos aqui ao conceito de "campo discursivo" no trabalho de Dominique Maingueneau (2008, 2010), que propõe uma releitura da teoria dos campos de Pierre Bourdieu, destacando a pertinência de se pensar relações entre atores, posições e lutas pela autoridade em termos de identidade enunciativa, ou seja, diferentes posicionamentos em interação que constituem fontes de enunciados que devem assumir os embates próprios do campo, definindo e legitimando seu próprio lugar de enunciação.

4 Nessa concepção teórica, o "discurso" concerne à relação entre "formação discursiva" e "superfície discursiva": em outros termos, trata-se do conjunto virtual de enunciados que podem ser produzidos a partir das restrições de uma formação discursiva dada.

5 Segundo pesquisa de Angela Zamin (2014), embora não se trate de elementos consensuais, há caracteristicas gerais que costumam ser associadas ao jornalismo de referência por pesquisadores que se debruçam sobre o tema, tais como: gozar de prestígio e tradição; voltar-se para a economia, assuntos internacionais e política, com ênfase nesta última; pressupor, como público, leitores competentes do mundo público; possuir índices elevados de tiragem e circulação; e conceder importância e espaço significativos para artigos opinativos (ZAMIN, 2014). 6 O periodo de observação foi definido de modo a cobrir um periodo extenso o bastante para comportar regularidades discursivas e o mais próximo o possivel da atualidade, tendo como ponto de partida o ano que marca o final da censura prévia à imprensa no Brasil. 7 Convém observar que o corpus analítico em foco neste artigo foi configurado a partir de um conjunto previamente constituido de 712 matérias jornalísticas publicadas entre 1978 e 2018 pelos três veículos, examinado em sua totalidade em pesquisa de doutorado desenvolvida junto ao Programa de Pós-Graduação em Ciências da Comunicação da Universidade de São Paulo.

8 Sigla para "lésbicas, gays, bissexuais e transgênero". Optamos por empregar a denominação "LGBT" neste trabalho por se tratar de nomenclatura recorrente na cobertura jornalistica de grande parte do periodo analisado e mostrar-se predominante entre as matérias do corpus; ressaltamos, entretanto, a existência de denominações mais inclusivas, às quais movimentos sociais têm dado preferência nos últimos anos, tais como "LGBTQIA+", sigla que abrange também pessoas queer, intersexuais, assexuais e mais.
} 
e marcos representativos da implantação de políticas públicas de gênero no Brasil (eixo 4).9

Após um primeiro rastreamento exaustivo das referências aos eixos em foco nas capas dos jornais (caso dos eixos 1 a 3, assim recortados diante do elevado número de ocorrência sobre os eventos em questão) ou por meio de palavras-chave específicas em toda a extensão dos veículos (caso do eixo 4, assim constituido devido ao baixo número de menções aos marcos de políticas públicas de gênero nas primeiras páginas dos jornais), foram selecionados, para a constituição do corpus analítico deste artigo, textos nos quais debates sobre diferenças de gênero aparecessem de forma mais extensa e/ou aprofundada.

Chegou-se, dessa forma, a um conjunto de 60 textos, entre reportagens e suplementos especiais, que constituem objeto das análises apresentadas no presente trabalho. ${ }^{10}$ Desses textos, 29 contemplam o eixo temático 1; dez, o eixo 2; um, o eixo 3; e vinte, o eixo 4. Além disso, 20 textos foram publicados por O Estado de S. Paulo; 25, pela Folha de S.Paulo; e 15, por O Globo. Em relação à sua distribuição temporal, seis textos foram veiculados entre 1979 e a década de 1980; cinco, nos anos 1990; 23, nos anos 2000; e 26, nos anos 2010. Tais diferenças quantitativas devem-se às próprias singularidades verificadas em termos da presença de cada eixo temático na cobertura dos jornais, da quantidade de matérias localizadas em cada veículo (a Folha de S.Paulo é o jornal em que obtivemos o maior número de achados, enquanto em O Globo foi localizado um número menor de ocorrências) e da concentração de textos ao longo do periodo pesquisado, marcado por um aumento gradual do número de matérias jornalísticas que visibilizam minorias sexuais e de gênero.

Mais uma vez, longe de pretender apagar as especificidades das formas de materialização das opressões vivenciadas entre mulheres e LGBTs e no interior desses grupos, as quais devem ser consideradas sobretudo diante do entrelaçamento de formas simultâneas de marcação da diferença (como gênero, classe e raça), a opção metodológica por focalizar a visibilidade conferida a mulheres e a LGBTs em eixos temáticos da cobertura jornalística justifica-se porque a ênfase conferida a questões relacionadas a essas duas categorias identitárias parece ser um traço constitutivo do modo como discursos que circulam na esfera pública midiatizada se posicionam em relação ao debate teórico e mesmo político em torno do conceito de gênero.

Em outras palavras, a opção por focalizar a cobertura jornalistica sobre mulheres e LGBTs busca abarcar um modo de articulação de sentidos por meio do qual se manifesta a abordagem da diferença na cultura midiática (e, em especial, em discursos jornalísticos), a saber, em sua manifestação em narrativas sobre desigualdade. Embora reconhecendo, portanto, que a complexidade do debate conceitual em torno de gênero em muito extrapole a abordagem das problemáticas vivenciadas por minorias ou maiorias minorizadas, este artigo focaliza duas categorias identitárias (mulher e LGBT), tomadas em suas conformações nativas, como ponto de partida à discussão sobre a formação de discursos potencialmente vinculados a gênero na imprensa brasileira. Dessa forma, as contradições e complexidades inerentes à mobilização de tais classificações e à fixação de seus limites em discursos do campo do jornalismo são de interesse desta pesquisa.

Além disso, cabe observar que nosso percurso metodológico estrutura-se de modo inverso em relação àquele percorrido por Maingueneau

\footnotetext{
9 Em relação ao eixo temático 4, foram considerados os seguintes marcos representativos do debate sobre políticas públicas de gênero no Brasil: criação do Conselho Nacional dos Direitos da Mulher (1985); lançamento do Programa Nacional de Prevenção e Combate à Violência Doméstica e Sexual (1996); criação do Conselho Nacional de Combate à Discriminação (2001); criação da Secretaria de Políticas para Mulheres (2003); lançamento do Programa Brasil Sem Homofobia (2004); promulgação da lei "Maria da Penha" - Lei n. ${ }^{\circ} 11.340 / 2005$ (2006); instituição das diretrizes nacionais para o processo transexualizador no SUS (2008); lançamento do Plano Nacional de Promoção da Cidadania e Direitos Humanos de LGBT - "Plano LGBT" (2009); instituição da Política Nacional de Saúde Integral de LGBT no âmbito do Sistema Único de Saúde (2011); reconhecimento da união homoafetiva pelo Supremo Tribunal Federal como entidade familiar (2011): e promulgação da chamada "Lei do Feminicídio" - Lei n. ${ }^{\circ}$ 13.104/2015 (2015)

10 Ao longo do artigo, as matérias jornalísticas listadas, em notas de rodapé, serão indicadas por meio de seus títulos, veiculos e datas de publicação, com o intuito exclusivo de evidenciar a constituição do corpus de análise e a incidência geral de aspectos identificados no universo da pesquisa.
} 
(2008) em suas análises sobre o discurso religioso: enquanto o ponto de partida do autor é a assunção da existência de um par opositivo de discursos (discurso jansenista e discurso do humanismo devoto), dos quais cabe ao analista descrever as regras de formação, este trabalho parte de uma ampla profusão de enunciados cuja única unidade de partida é dada pelo fato de abordarem um núcleo temático comum. Nosso objetivo, nesse sentido, é identificar, nos enunciados jornalísticos analisados, a existência de unidades e/ou distinções para além dos conteúdos tratados, ou seja, caracterizá-los em um nivel propriamente discursivo.

\section{Uma problemática discursiva}

Considerando que o exame da enunciabilidade de um discurso passa pela identificação das restrições que o conformam, indagamos se e de que modo a construção de enunciados que visibilizam mulheres e LGBTs na imprensa de referência brasileira, tomados diacronicamente, reflete a coerção exercida por transformações discursivas mais amplas; da mesma forma, esperamos descrever os contornos e a natureza das possiveis coerções e suas transformações ao longo do tempo.

Por "coerção", vale ressaltar, referimo-nos a uma dinâmica própria de fenômenos discursivos, como descritos por Foucault (2008) e Maingueneau (2008), que caracteriza a formação de um discurso como o efeito de restrições semânticas e rege os processos de interação entre discursos e campos discursivos. Tomando essa formulação como pressuposto teórico, esta pesquisa parte de dois fenômenos relativamente recentes no universo discursivo ${ }^{11}$ como origem de formações discursivas potencialmente capazes de transformar os modos por meio dos quais jornais de referência brasileiros enunciam sobre mulheres e LGBTs. Ao longo deste artigo, como veremos, tensionamos e problematizamos o alcance de tais interações discursivas, chamando a atenção ainda para a existência de outras formações discursivas cujo poder de interdição faz-se sentir na construção de enunciados jornalísticos sobre as categorias identitárias em foco.

O primeiro fenômeno no universo discursivo a ser destacado diz respeito ao que Nancy Fraser (2006) denomina como a emergência de um novo imaginário político marcado pela centralidade adquirida por demandas por reconhecimento na luta por justiça social. Embora em termos práticos seja impossivel, na dimensão deste artigo, abordar a complexidade desse processo, bem como os próprios dissensos teóricos a respeito de sua constituição, pode-se destacar, enquanto manifestação de um imaginário de reconhecimento, a visibilidade adquirida por disputas e politicas identitárias (HALL, 1997; WOODWARD, 2014), que podem assumir feições tanto afirmativas quanto transformativas (HALL, 1997). Cabe ainda notar que agentes ligados a diferentes campos do espectro político dedicam-se à destituição do que têm chamado de "identitarismos", tendência cuja face mais evidente pode ser encontrada no fenômeno em escala global da "virada conservadora", discutido na teoria do cultural backlash (NORRIS; INGLEHART, 2019).

Ao mesmo tempo, um segundo fenômeno a ser destacado como fonte de rearticulações transversais a diversos campos no universo discursivo diz respeito à diferenciação entre sexo (categoria biológica que se volta a uma abordagem essencializante da natureza) e gênero (categoria que remete à construção histórica, social e política e implica uma abordagem relacional) que se processa a partir dos anos 1980, no contexto da chamada segunda onda feminista (MATOS, 2008; HOLLANDA, 2019). Nasceram assim os chamados estudos de gênero.12 Tributário dos estudos de linguagem,

No seu uso mais recente, "gênero" parece ter aparecido primeiro entre as feministas americanas que queriam insistir no caráter fundamentalmente social das distinções baseadas no sexo. A palavra indicava rejeição

\footnotetext{
11 Por "universo discursivo", Maingueneau (2008, p. 33) refere-se ao "conjunto de formações discursivas de todos os tipos que interagem numa conjuntura dada". Ainda que não possa ser aprendido em sua totalidade, trata-se de um "conjunto finito", que define uma "extensão máxima", um dado "a partir do qual serão construidos os dominios suscetiveis de ser estudados, os 'campos discursivos'".

12 Não é possivel, nas dimensões deste artigo, apresentar os trabalhos fundamentais do campo; não obstante, destacamos, como referências seminais aos estudos de gênero, os trabalhos de: BUTLER, 2001, 2008; HARAWAY, 2009; LAURETIS, 2019.
} 
ao determinismo biológico implícito no uso de termos como "sexo" ou "diferença sexual" (SCOTT, 2019, p. 50).

Tanto a emergência de discursos teóricos e políticos que assumem de maneira central o conceito de gênero quanto a conformação de discursos de reconhecimento implicam em modos específicos de enunciar e novas formas de articular discursivamente categorias de pertencimento decorrentes de reposicionamentos das próprias identidades, o que coloca desafios aos modos por meio dos quais os enunciados da imprensa de referência, terreno alheio em relação àquele em que emergem as rearticulações discursivas em foco e ainda fortemente assentada em categorias fundantes da modernidade - como nação e universalismo -, produzem sentidos na contemporaneidade. ${ }^{13} \mathrm{Em}$ especial, propomos analisar neste trabalho matérias que visibilizam mulheres e LGBTs como objeto privilegiado ao exame das negociações entre diferentes discursividades processadas nos jornais.

Para tanto, mobilizamos procedimentos analíticos voltados à caracterização do que Maingueneau (2008) define como "semântica global" do discurso, isto é, à identificação de sistemas semânticos que compõem identidades discursivas por meio da caracterização, de maneira integrada, de diversos planos discursivos. Com base nas dimensões do enunciado elencadas por Maingueneau (2008), delimitamos três planos discursivos particularmente relevantes ao objeto e à problemática em foco nesta pesquisa, os quais serão tomados de forma adaptada às necessidades empíricas específicas deste estudo. Assim, as análises apresentadas nas próximas páginas buscam compreender como se concretizam semanticamente os enquadramentos temáticos, as marcas de intertextualidade e os modos de coesão nos enunciados jornalísticos focalizados.

\section{2 (Re)enquadramentos temáticos}

A análise dos enquadramentos temáticos em enunciados jornalísticos desempenha papel fundamental às leituras que traçamos neste trabalho: por se referir a aspectos talvez mais palpáveis do que todos os outros planos, o exame dessa dimensão discursiva oferece-nos indícios significativos da conformação de diferentes lógicas de mediação interdiscursiva que caracterizam os enunciados do corpus.

Partindo de uma definição básica - tema como "aquilo de que um discurso trata" -, Maingueneau (2008, p. 81) destaca a importância de se considerar o tratamento semântico conferido tanto aos temas impostos pelo campo discursivo quanto aos temas especificos de um discurso, sendo que ambos os tipos são integrados semanticamente por um sistema de restrições. Em nosso caso, o conjunto de temas impostos - temas de que o campo discursivo jornalístico não pode deixar de tratar - é extenso e de estabilidade inevitavelmente limitada, já que a seleção de pautas se baseia em um sentido de interesse público abrangente e constantemente remodelado - e remodelável -, além de profundamente tensionado pela emergência e circulação de novos discursos.

Nesse sentido, o exame da cobertura de jornais de referência indica que, por um lado, já no final da década de 1970, questões relacionadas às vivências de mulheres apresentavam-se como temas impostos ao jornalismo de referência, configuração presente em seis matérias de nosso corpus. ${ }^{14}$ Não obstante, essas mesmas temáticas recebiam tratamento quase sempre marginal nos veículos de imprensa, como fica evidente se observarmos o espaço ocupado pelas matérias nas capas dos jornais, por exemplo (SCABIN, 2020). Dois fatores parecem determinar esse enquadramento temático: o caráter recente de questões femininas e feministas como pauta midiática - sobretudo, com os contornos iden-

\footnotetext{
13 A respeito do deslocamento de concepções fundadoras da Modernidade pelo imaginário político contemporâneo e, em especial, pela emergência do ideário de diversidade, da fragmentação das identidades modernas e das políticas identitárias, ver: ORTIZ, 2015: WOODWARD, 2014: HALL, 2019, 1997.

14 Referimo-nos aos seguintes textos, publicados entre 1979 e 1988: "Mulheres comemoram seu dia exigindo uma transformação" (FoLha de S.Paulo, 8 de março de 1979); "As feministas brasileiras" (O Globo, 8 de março de 1980); "O que as mulheres tanto procuram?" (Folha de S.Paulo, 8 de março de 1981); "Direitos da mulher, uma batalha de Ruth Escobar" (O Globo, 7 de julho de 1985); "Mulheres criticam cartaz contra Aids" (Folha de S.Paulo, 28 de fevereiro de 1988); e "Dia da mulher, 'dia de avanços'" (O Estado de S. Paulo, 9 de março de 1988).
} 
titários que o tema adquire no final do século $X X$ - e sua filiação a um imaginário político que desloca concepções politicas modernas ${ }^{15}$ às quais se vinculam discursos constituintes ${ }^{16}$ do jornalismo de referência.

Já na década de 1990, maior diversidade de subtemas passa a ser abordada nos textos analisados: além de discussões sobre estupro e violência, aparecem questões relacionadas à desigualdade salarial entre homens e mulheres, formação e escolaridade feminina e qualificação da mulher no mercado de trabalho. Trata-se de um período marcado pela entrada em cena de temas tradicionais do noticiário econômico em pautas sobre questões femininas/feministas, abordados principalmente a partir de dados estatísticos e pesquisas demográficas. Por um lado, predomina ainda um tratamento semântico, recorrente na década anterior, fortemente ancorado em categorias políticas modernas, como "nação" e "Estado", com a abordagem de estratégias de gestão da população e do reconhecimento do papel de instituições tradicionais. ${ }^{17}$ Por outro lado, discursos do campo econômico parecem cada vez mais interditar discursos político-ativistas, cujas vozes apareciam de modo mais frequente nos anos $1980 .{ }^{18} \mathrm{~A}$ década de 1990 também representa um momento decisivo ao aparecimento de referências à comunidade LGBT entre as matérias do corpus. No entanto, a abordagem do tema restringia-se predominantemente a textos sobre a Parada do Orgulho LGBT de São Paulo, com foco em aspectos cotidianos do evento, como número de participantes. ${ }^{19}$

Ao mesmo tempo, as articulações semânticas presentes na cobertura jornalística dos anos 1990 e início dos 2000 sugerem que, no momento em que vivências de mulheres e LGBTs passam a ser enquadradas tematicamente à luz de discursos do campo econômico, ${ }^{20}$ elas passam a ocupar uma posição cada vez menos marginal. Não à toa, nos anos 2000, verifica-se uma queda na visibilidade conferida ao papel desempenhado pelo Estado e por políticas públicas na garantia dos direitos de mulheres e LGBTs, sobretudo em comparação à cobertura realizada nos anos 1980 e início dos 1990 sobre temas como a inclusão de pautas femininas na constituinte e a atuação de órgãos como o Conselho Nacional dos Direitos da Mulher (CNDM). Indo além, torna-se recorrente, na primeira década do novo século, o enquadramento temático da desigualdade de gênero sob uma lógica de mercado sintonizada com perspectivas neoliberais, ${ }^{21}$ configuração identificada em 13 textos de nosso corpus. ${ }^{22}$

Um exemplo é a reportagem "Abrindo portas", de Julio Wiziack e Claudia Rolli, publicada pela Folha de S.Paulo, em 7 de junho de 2009. Como sugere o subtítulo - "Com sacrifício, executivos rompem preconceito, saem do armário e conquistam espaço no mercado de trabalho" -, a matéria enfatiza aspectos do mundo corporativo e dá visibilidade a trajetórias individuais - com direito a uma profusão de citações em discurso direto dos

\footnotetext{
15 A respeito do deslocamento de concepções fundadoras da Modernidade pelo imaginário político contemporâneo e, em especial, pela emergência do ideário de diversidade, da fragmentação das identidades modernas e das políticas identitárias, ver: ORTIZ, 2015: WOODWARD, 2014; HALL, 2019; 1997

16 Relacionada às problemáticas do interdiscurso, a teoria do discurso constituinte de Maingueneau (2010) busca dar conta do caráter heterogêneo do universo discursivo, que deve ser entendido como formado por zonas com propriedades especificas. Os discursos constituintes são aqueles que pertencem, portanto, a uma zona discursiva que opera como "autoridade", reivindicando para si uma forma de transcendência, pois se autorizam a partir de si mesmas.

17 É o caso das matérias "Um milhão de adolescentes dão à luz por ano no Brasil, diz IBGE" (Folha de S.Paulo, 9 de março de 1991) e "FHC reclama dos baixos salários pagos às mulheres" (O Globo, 9 de março de 1996).

18 É o caso das matérias "FHC reclama dos baixos salários pagos às mulheres" (O Globo, 9 de março de 1996) e "Mulheres superam homens em escolarização" (O Estado de S. Paulo, 8 de março de 1998).

19 É o caso da matéria "Dia do Orgulho Gay reúne 2 mil em SP" (O Estado de S. Paulo, 29 de junho de 1998)

20 Este enquadramento temático será aqui referido como [gênero-economia].

21 Este enquadramento temático será aqui referido como [gênero-mercado].

22 Referimo-nos aos seguintes textos, publicados na década de 2000: "OIT: mulheres executivas são só 3\% no mundo" (O Globo, 9 de março de 2001); "Cai diferença de renda entre homem e mulher" (O Globo, 8 de março de 2001); "O novo perfil da mulher brasileira" (O Estado de S. Paulo, 8 de março de 2002); "Cada vez mais trabalham fora e pagam despesas" (O Estado de S. Paulo, 8 de março de 2002): "Executiva ganha espaço nas empresas" (O Globo, 8 de março de 2002); "Região da Frei Caneca vira 'point' GLS" (Folha de S.Paulo, 22 de junho de 2003); "Brasileiras conquistam vagas nas empresas" (O Estado de S. Paulo, 8 de março de 2004); "Jeito feminino, o segredo do sucesso" (O Estado de S. Paulo, 8 de março de 2004); "O que elas querem" (Folha de S.Paulo, 8 de março de 2005); Mulheres (O Estado de S. Paulo, 8 de março de 2006); "Que feminismo é esse?" (Folha de S.Paulo, 8 de março de 2007); "Mercado gay no Brasil é muito pouco explorado, diz InSearch" (Folha de S.Paulo, 10 de junho de 2007); e" Abrindo portas" (Folha de S.Paulo, 7 de junho de 2009).
} 
personagens entrevistados - e histórias sucesso profissional e ascensão econômica. A composição da página e a fotografia de um personagem vestido em traje social reforçam o tratamento semântico voltado à valorização de trajetórias individuais na construção da pauta. Além disso, o Programa Brasil sem Homofobia é citado apenas no décimo parágrafo como um elemento secundário - e passivo - das conquistas obtidas pela comunidade LGBT: "Desde que o governo federal implementou o programa 'Brasil sem Homofobia', o Ministério do Trabalho e Emprego (MTE) passou a receber mais reclamações sobre discriminação nas empresas" (WIZIACK; ROLLI,2009).

Os anos 2010, por sua vez, são marcados por novos aprofundamentos em relação aos enquadramentos temáticos verificados na década anterior. Em primeiro lugar, amplia-se o espaço para matérias que articulam vivências de mulheres e LGBTs a questões de mercado, como aquelas relacionadas ao mercado financeiro ("As lobas de Wall Street", da Folha de S.Paulo de 8 de março de 2014) e empreendedorismo ("Mulher empreendedora inova e retém mais talentos", também da Folha de S.Paulo, do dia 8 de março de 2011); é também nessa época que a expressão "empoderamento" começa a aparecer na cobertura dos jornais, em geral associada a iniciativas individuais, à afirmação de traços identitários e, muitas vezes, à ascensão econômica, como na matéria "Quero 'empoderar' mulheres de baixa renda", da Folha de S.Paulo de 8 de março de 2011. ${ }^{23}$ O (sub)tema do "empoderamento" e (sub) temas ligados ao sucesso individual apresentam evidente afinidade semântica: em ambos os casos, focalizam-se processos de superação de injustiças de gênero que não passam pela transformação de estruturas político-sociais.
É também na última década que identificamos um ponto de virada significativo: é neste momento que a temática da "diversidade"24 torna-se central nos enunciados jornalísticos, configuração que pode ser identificada de maneira clara em pelo menos três matérias do corpus no periodo. ${ }^{25}$ Entretanto, mais do que operar como tema imposto condizente com as regras de formação dos enunciados do jornalismo de referência, a "diversidade" - trabalhada segundo uma chave de afirmação da "diferença" - parece emergir como tema específico, dada a relação privilegiada que desempenha a partir de então com restrições semânticas globalmente construidas nos textos analisados. Em outras palavras, a lógica semântica da /diferença/ desdobra-se em cascata, atuando simultaneamente sobre diferentes planos discursivos.

Um exemplo é a reportagem, publicada em 8 de março de 2017 pelo Estado, que se intitula "Como vivem as brasileiras pelo mundo". O texto traz relatos de mulheres - brancas, lésbica, negra, muçulmana - que vivem em diversos contextos sobre o que é ser mulher e brasileira em diferentes países, enfatizando não apenas a diversidade de perfis, como também a problematização da identidade à luz da diferença. Por isso, a reportagem ilustra uma tendência significativa: os anos 2010 correspondem ao momento em que "gênero" se converte em categoria semântica capaz de extrapolar a compartimentação do tema "gênero/mulher" e passa a agregar de fato questões ligadas tanto à condição feminina quanto à população LGBT; participam dessa construção de sentido componentes fortemente ligados à valorização da "diferença", da "multiplicação das diferenças" ou da "diferença dentro da diferença", princípios que se desdobram semanticamente sobre os planos discursivos.

\footnotetext{
23 Além do exemplo citado, a temática do empoderamento pode ser identificada de maneira clara em pelo menos mais quatro textos publicados na década de 2010 que fazem parte de nosso corpus: "Mulher empreendedora inova e retém mais talentos" (Folha de S.Paulo, 8 de março de 2011); "Lugar de mulher é na cozinha... E na adega, no alambique e no terreiro de café" (O Estado de S. Paulo, 8 de março de 2012$)$; "O desafio de quem quer definir seu próprio destino" (O Estado de S. Paulo, 8 de março de 2018); e "Sempre em frente" (O Globo, 8 de março de 2016). 24 Um exemplo do tratamento semântico conferido anteriormente ao tema pode ser encontrado na reportagem "Respeito à diversidade aprende-se na infância", publicada pela Folha de S.Paulo em 28 de junho de 2001; no texto, "diversidade" emerge ainda como tentativa de se traduzir uma discussão até então alheia - ainda que em alguma medida já imposta - à economia semântica própria do jornalismo de referência (KLINGER, 2001).

25 Referimo-nos aos seguintes textos, publicados na década de 2010: "Diversidade é maior entre casais gays" (O Estado de S. Paulo, 2 de junho de 2013); "Como vivem as brasileiras pelo mundo" (O Estado de S. Paulo, 8 de março de 2017); e "Estudantes com identidade" (O Globo, 13 de agosto de 2017).
} 
Dessa forma, a década de 2010 é marcada pelo tensionamento de categorias identitárias. Nesse contexto, podem ser identificados dois modos pelos quais os temas da "diversidade" e da "diferença" se incorporam aos enunciados. Em primeiro lugar, com o borramento de hierarquias político-sociais e a colocação de "diversas diferenças" lado a lado, em pé de igualdade, a manifestação da /diferença/ em muitos textos do corpus revela estreita afinidade semântica com os (sub)temas do "empoderamento", das "trajetórias individuais de sucesso" e com o enquadramento [gênero-mercado]. Menos recorrente, uma segunda manifestação da/diferença/ pode ser identificada em textos nos quais as hierarquias de poder são evidenciadas: é o que ocorre em poucas reportagens sobre desigualdades existentes entre mulheres brancas e negras ${ }^{26}$ e a invisibilidade trans na comunidade $\mathrm{LGBT}^{27}$, por exemplo.

\section{Diversificação de discursos em marcas de intertextualidade}

Marcas de intertextualidade dizem respeito a um plano discursivo em relação ao qual se observam menos variações do que aquelas verificadas em relação aos enquadramentos temáticos. Isso porque referimo-nos a dimensões que dizem respeito a aspectos genéricos e estilísticos relativamente estabilizados no jornalismo de referência a partir do acionamento de discursos internos ao campo discursivo jornalístico, como aqueles que se traduzem na definição da tipologia e citação das fontes, em regras de estruturação dos enunciados etc.

Por isso, as observações apresentadas neste item tratam de deslocamentos e inversões de ênfase, de uma década a outra, dentro de um conjunto mais amplo de padrões de intertextualidade possiveis. Tais movimentos dizem respeito essencialmente a rearticulações em relações estabelecidas com formações discursivas externas ao campo jornalístico. Assim, os campos/ discursos predominantes entre as referências presentes nos enunciados jornalísticos de nosso corpus podem ser assim discriminados:

a) década de 1980: discurso político institucional (presente em quatro textos); discurso político: ativismo (presente em três textos);

b) década de 1990: discurso econômico (presente em dois textos); discurso técnico-científico (presente em um texto); discurso politico institucional (presente em um texto); discurso político: ativismo (presente em um texto);

c) década de 2000: discurso econômico (presente em treze textos); discurso técnico-científico (presente em onze textos); discurso corporativo/empresarial (presente em sete textos); discurso político institucional (presente em cinco textos); discurso político: ativismo (presente em quatro textos); discurso acadêmico (presente em três textos);

d) década de 2010: discurso político: ativismo (presente em doze textos); discurso técnico-científico (presente em onze textos); discurso político institucional (presente em dez textos); discurso jurídico (presente em nove textos); discurso corporativo/empresarial (presente em cinco textos); discurso econômico (presente em quatro textos); discurso acadêmico (presente em três textos).

Destaca-se, ao longo dos anos, a perda do espaço conferido às referências ao discurso político institucional. O periodo entre final dos anos 1970 e anos 1980 corresponde ao momento de maior politização dos debates sobre a condição da mulher nos jornais, com forte sentido de coletividade e cobrança de ações por parte do Estado nas matérias. ${ }^{28} \mathrm{~A}$ partir dos anos 1990 , o discurso político institucional parece ser interditado à medida que ganham força um discurso técni-

26 É o caso, no corpus de análise, da reportagem "Morte de mulheres negras avança 54\%" (O Estado de S. Paulo, 9 de novembro de 2015).

27 É o caso, no corpus de análise, da reportagem "Trans se dizem excluídos da Parada Gay" (Folha de S.Paulo, 7 de junho de 2015).

28 É possivel verificar tal configuração, no caso do corpus de análise, em seis textos publicados entre o final dos anos 1970 e a década de 1980: "Dia da mulher, 'dia de avanços'" (O Estado de S. Paulo, 9 de março de 1988); "'As feministas brasileiras" (O Globo, 9 de março de 1980); "Direitos da mulher, uma batalha de Ruth Escobar" (O Globo, 7 de julho de 1985); "Mulheres comemoram seu dia exigindo uma transformação" (Folha de S.Paulo, 8 de março de 1979); "O que as mulheres tanto procuram?" (Folha de S.Paulo, 8 de março de 1981); e "Mulheres criticam cartaz contra Aids" (Folha de S.Paulo, 28 de fevereiro de 1988). 
co-científico - referido à exaustão em matérias que abordam a condição feminina no país a partir de resultados de levantamentos conduzidos por órgãos de pesquisa, com destaque para o IBGE - e, principalmente, discursos econômicos ${ }^{29}$ presentes em matérias que vinculam grandes temas econômicos, como emprego e remuneração, à discussão sobre a condição da mulher. Tais configurações reforçam semanticamente a centralidade adquirida pelo enquadramento temático [gênero-economia] na mesma época.

Já nos anos 2000, a prevalência de discursos corporativo-empresariais ${ }^{30}$ reforça a emergência de um enquadramento [gênero-mercado] fortemente influenciado por perspectivas neoliberais. Perdem espaço e relevância tanto o discurso político-institucional quanto o discurso técnico-científico, evidenciando o apagamento paulatino, nas matérias que abordam questões de gênero, da busca de interfaces com o poder público, do papel do Estado, da luta por soluções coletivas.

Será na década seguinte, não obstante, que se pode identificar a consolidação de discursos identitários (isto é, que se articulam centralmente em torno de categorias de pertencimento) no jornalismo de referência. No caso das marcas de intertextualidade externa, os arranjos entre os discursos acionados nas matérias seguem os princípios de um tratamento semântico pautado pela /diferença/, como fica evidente se consideramos a maior diversidade de campos discursivos aos quais recorrem os enunciados jornalisticos no período, justapostos lado a lado como que em alusão à pluralidade de perspectivas a partir das quais se enuncia sobre gênero. Nesse momento, a prevalência de discursos político-ativistas, ${ }^{31}$ longe de representar o principal local de ancoragem dos sentidos presentes nos enunciados das matérias, opera no sentido de multiplicar os lugares de / diferença/ representados: em arranjos semânticos nos quais todas as vozes são válidas, esses discursos relativizam-se uns aos outros na justaposição com campos discursivos outros.

Na reportagem "O desafio de quem quer definir seu próprio destino", de Isabela Palhares e Juliana Diógenes, publicada em 8 de março de 2018 no

29 É possivel verificar a presença de um discurso técnico-científico e/ou de discursos econômicos, no caso do corpus de análise, em 30 textos publicados a partir dos anos 1990: "Mulheres superam homens em escolarização" (O Estado de S. Paulo, 8 de março de 1998): "O novo perfil da mulher brasileira" (O Estado de S. Paulo, 8 de março de 2002); "Cada vez mais trabalham fora e pagam despesas" ( $O$ Estado de S. Paulo, 8 de março de 2002); "Brasileiras conquistam vagas nas empresas" (O Estado de S. Paulo, 8 de março de 2004); "Jeito feminino, o segredo do sucesso" (O Estado de S. Paulo, 8 de março de 2004); "Após 30 anos de luta, movimento gay quer mais que só um dia de Parada" (O Estado de S. Paulo, 25 de maio de 2008); "Lei Maria da Penha não reduz mortes" (O Estado de S. Paulo, 26 de setembro de 2013): "Diversidade é maior entre casais gays" (O Estado de S. Paulo, 2 de junho de 2013): "Morte de mulheres negras avança 54\%" (O Estado de S. Paulo, 9 de novembro de 2013); "O desafio de quem quer definir seu próprio destino" (O Estado de S. Paulo, 8 de março de 2018); "FHC reclama dos baixos salários pagos às mulheres" (O Globo, 9 de março de 1996); "Cai diferença de renda entre homem e mulher" (O Globo, 8 de março de 2001); "OIT: mulheres executivas são só 3\% no mundo" (O Globo, 9 de março de 2001); "Executiva ganha espaço nas empresas" (O Globo, 8 de março de 2002); "Pesquisa: 99\% têm preconceito contra gays" (O Globo, 8 de fevereiro de 2009 ); "O fim do silêncio" (O Globo, 25 de julho de 2016); "Na mira de covardes" (O Globo, 8 de março de 2017); "Um milhão de adolescente dão à luz por ano no Brasil, diz IBGE" (Folha de S.Paulo, 8 de março de 2001); "Região da Frei Caneca vira 'point' GLS" (Folha de S.Paulo, 22 de junho de 2003): Sinal fechado para o preconceito (Folha de S.Paulo, 8 de março de 2004); "O que elas querem" (Folha de S.Paulo, 8 de março de 2005); "Que feminismo é esse?" (Folha de S.Paulo, 8 de março de 2007); "Mercado gay no Brasil é muito pouco explorado, diz InSearch" (Folha de S.Paulo, 10 de junho de 2007); "Abrindo portas" (Folha de S.Paulo, 7 de junho de 2009); "Mulher empreendedora inova e retém mais talentos" (Folha de S.Paulo, 8 de março de 2011); "As lobas de Wall Street" (Folha de S.Paulo, 8 de março de 2014); "País patina no combate à homofobia e vira lider em assassinato de LBGTs" (Folha de S.Paulo, 17 de maio de 2017); "Casais gays antecipam casamento com medo de perder direitos sob Bolsonaro" (Folha de S.Paulo, 5 de novembro de 2018); "Salário mais baixo para as mulheres reduz o crescimento" (Folha de S.Paulo, 8 de março de 2018); e "Mulher de números" (Folha de S.Paulo, 8 de março de 2018).

30 É possivel verificar a presença de discursos corporativo-empresariais, no caso do corpus de análise, em onze textos publicados a partir dos anos 2000: "Brasileiras conquistam vagas nas empresas" (O Estado de S. Paulo, 8 de março de 2004); "Jeito feminino, o segredo do sucesso" (O Estado de S. Paulo, 8 de março de 2004); "Lugar de mulher é na cozinha... E na adega, no alambique e no terreiro de café" (O Estado de S. Paulo, 8 de março de 2012); "OIT: mulheres executivas são só 3\% no mundo" (O Globo, 9 de março de 2001); "Executiva ganha espaço nas empresas" (O Globo, 9 de março de 2002); "Sinal fechado para o preconceito" (Folha de S.Paulo, 8 de março de 2004): "O que elas querem" (Folha de S.Paulo, 8 de março de 2005): "Abrindo portas" (Folha de S.Paulo, 7 de junho de 2009): "Mulher empreendedora inova e retém mais talentos" (Folha de S.Paulo, 8 de março de 2011); "Quero 'empoderar' as mulheres de baixa renda" (Folha de S.Paulo, 8 de março de 2011); e "As lobas de Wall Street" (Folha de S.Paulo, 8 de março de 2014).

${ }_{31}$ É possível verificar a presença de discursos político-ativistas entre textos publicados nos anos 2010, no caso do corpus de análise. em doze textos, a saber: "Diversidade é maior entre casais gays" (O Estado de S. Paulo, 2 de junho de 2013); "Morte de mulheres negras avança 54\%" (O Estado de S. Paulo, 9 de novembro de 2015); "Como vivem as brasileiras pelo mundo" (O Estado de S. Paulo, 8 de março de 2017); "O desafio de quem quer definir seu próprio destino" (O Estado de S. Paulo, 8 de março de 2018); "Multidão contra a homofobia" (O Globo, 27 de junho de 2011); "Longo caminho à igualdade" (O Globo, 9 de março de 2015); "Estudantes com identidade" (O Globo, 13 de agosto de 2017); "Quero 'empoderar' as mulheres de baixa renda" (Folha de S.Paulo, 8 de março de 2011); "Trans se dizem excluidos da Parada Gay" (Folha de S.Paulo, 7 de maio de 2015); "País patina no combate à homofobia e vira lider em assassinato de LBGTs" (Folha de S.Paulo, 17 de maio de 2017); "Quem não é homem?" (Folha de S.Paulo, 23 de agosto de 2017); e "Casais gays antecipam casamento com medo de perder direitos sob Bolsonaro" (Folha de S.Paulo, 5 de novembro de 2018. 
Estadão, por exemplo, uma declaração de Marlise Matos, coordenadora do Núcleo de Estudos e Pesquisas Sobre a Mulher da UFMG, aparece no último parágrafo como forma de comentário às histórias de vida de cinco jovens mulheres em torno das quais se articula a matéria como um todo, subordinando-se aos sentidos extraídos dos relatos de trajetórias pessoais: "Elas querem ter o poder de definir seu próprio projeto de vida" frase que inspira o título da reportagem.

\section{Tensionamentos de modelos de coesão: narrativização e histórias de vida}

Sabendo que o "modo de coesão" relaciona-se não apenas à distribuição de um discurso em gêneros constituidos como também à organização interna dos textos (MAINGUENEAU, 2008), a adoção de uma perspectiva histórica na análise do corpus focalizado neste trabalho revela tensionamentos de modelos textuais estáveis que, em anos recentes, reforçam a consolidação de um modelo de restrições semânticas baseado em um principio de /diferença/.

Enquanto, até a primeira metade dos anos 2000, as matérias analisadas estruturavam-se predominantemente a partir da lógica jornalística da pirâmide invertida, temos um ponto de virada no final da década de 2000: em lugar do lide noticioso, passam a predominar, desde então, estratégias de encadeamento baseadas na narrativização, com ordenamento mais cronológico e valorização de personagens e suas histórias de vida. Como abertura das reportagens, tornam-se recorrentes pequenos relatos de personagens que ilustram as temáticas em foco. Essa tendência se apresenta nos três jornais de referência analisados, acentuando-se particularmente nos casos de O Globo e da Folha de S.Paulo. ${ }^{32}$
Uma guinada de tal tipo depende de processos discursivos complexos no interior do campo; de fato, em anos recentes, os jornais de referência têm buscado explorar, com maior frequência, modelos textuais que incluem estratégias mais "narrativas", como as que identificamos nesta pesquisa. Não obstante, a presença sistemática desse modo de estruturação nas matérias de nosso corpus a partir de fins dos anos 2000 , se não exclusiva de matérias sobre gênero, apresenta inegável afinidade com pautas identitárias. Além disso, é relevante o fato de o ponto de virada identificado nos modos de coesão das matérias corresponder justamente a momentos decisivos na conformação atual dos enunciados de nosso corpus do ponto de vista também dos enquadramentos temáticos e marcas de intertextualidade.

Uma das reportagens analisadas em que essa leitura se mostra com maior clareza intitula-se Estudantes com identidade. No texto, publicado no dia 13 de agosto de 2017 no jornal O Globo, a dimensão de afirmação das identidades representadas fica evidente já nos primeiros parágrafos:

Victor Oliveira nunca foi de sentar na primeira fileira nem no fundão da sala de aula. Ficava no meio. Falante, sempre rindo com os colegas, não escondia a contrariedade na hora da chamada. O nome dele não constava da lista de presença, mas sim o de batismo, no feminino. Aquela, diz ele, não existe mais. Aos 18 anos, o estudante do primeiro ano do ensino médio do Colégio Pedro II, na Zona Norte do Rio, acaba de conquistar o direito de ser tratado conforme sua identidade de gênero. Agora, quando o professor chama Victor Oliveira, ele não esconde a felicidade e responde: "presente".

- A gente já é julgado [sic] por 24 horas. Se o colégio não estivesse ao meu lado, eu não teria seguido em frente - emociona-se Victor, após chorar pelo corredor do colégio ao saber que o requerimento para a mudança tinha sido aceito e que os documentos com seu nome estarão prontos em breve (SOUTO, 2017, p. 43).

\footnotetext{
32 Tal tendência apresenta-se de modo particularmente pronunciado em dezesseis textos do corpus de análise, a saber: "Jeito feminino, o segredo do sucesso" (O Estado de S. Paulo, 8 de março de 2004); "Mulheres" (O Estado de S. Paulo, 8 de março de 2006); "Após 30 anos de luta, movimento gay quer mais que só um dia de Parada" (O Estado de S. Paulo, 25 de maio de 2008); "Mudança de sexo demora até 10 anos no Brasil Parada" (O Estado de S. Paulo, 29 de maio de 2016); "DPs não registram agressão à mulher; medida protetiva demora até 4 meses" (O Estado de S. Paulo, 7 de agosto de 2016); Como vivem as brasileiras pelo mundo (O Estado de S. Paulo, 8 de março de 2017); "O desafio de quem quer definir seu próprio destino" (O Estado de S. Paulo, 8 de março de 2018); "Longo caminho à igualdade" (O Globo 9 de março de 2015): "Sempre em frente" (O Globo, 8 de março de 2016); "Estudantes com identidade" (O Globo, 13 de agosto de 2017): "Abrindo portas" (Folha de S.Paulo, 7 de junho de 2009); As lobas de Wall Street (Folha de S.Paulo, 8 de março de 2014); "Quem não é homem?" (Folha de S.Paulo, 23 de agosto de 2017); "Fila para atendimento a trans no SUS impulsiona clínicas privadas" (Folha de S.Paulo, 28 de outubro de 2018); "Casais gays antecipam casamento com medo de perder direitos sob Bolsonaro" (Folha de S.Paulo, 5 de novembro de 2018); e "Mulher de números" (Folha de S.Paulo, 8 de março de 2018).
} 
Além disso, nesse exemplo, tanto texto quanto imagem reforçam a valorização da singularidade e diversidade de personagens, bem como suas dimensões subjetiva e identitária. As duas fotografias que acompanham a matéria apresentam entrevistados em ambiente escolar; em uma delas, vemos o estudante Victor Oliveira escrevendo seu nome sobre uma lousa. O enquadramento da foto valoriza o rosto de Victor, que olha diretamente para a câmera. Dessa forma, o foco da fotografia valoriza rosto e nome - dois dos principais loci de inscrição da identidade na cultura ocidental.

\section{Considerações finais}

Ao longo das análises, procuramos descrever as rupturas verificadas em enunciados de jornais brasileiros de referência sobre minorias sexuais e de gênero, a partir do exame de diferentes planos discursivos, considerando o intervalo temporal entre 1978 e 2018. Com esse gesto analítico, buscamos identificar quadros semânticos - sempre negociados - ligados a diferentes modos de formação dos enunciados, formas de coerção e trocas interdiscursivas. Entendemos que os diferentes arranjos identificados correspondem a momentos distintos na concretização de trocas entre o campo discursivo jornalístico - ou o jornalismo de referência, mais especificamente - e elementos da discursividade política contemporânea, em que pesem a emergência e o fortalecimento de discursos identitários, pautas feministas e reivindicações de movimentos LGBT em espaços midiáticos.

Nesse sentido, os anos 2010 destacam-se como cenário de emergência e estabilização de um posicionamento enunciativo no campo jornalístico a partir do qual passam a ser produzidos enunciados sobre as categorias identitárias em foco (mulheres e LGBTs) segundo um conjunto de restrições semânticas mais ou menos estável e delimitado. Por isso, consideramos que o período é marcado pela consolidação de uma nova formação discursiva no campo, caracterizada pela formação de enunciados em que categorias de pertencimento assumem novas formas de visibilidade relacionadas à focalização de demandas por reconhecimento cultural, à valorização do aspecto cultural/relacional das identidades e/ ou à representação da diferença em uma perspectiva de valorização da diversidade.

Como vimos na apresentação das constatações obtidas a partir do exame do corpus de pesquisa, há um sentido de /diferença/ que se mostra decisivo à constituição dessa nova formação discursiva. Entendemos que essa notação aponta para a existência de um operador (ou "núcleo semântico") aplicado e aplicável a diferentes eixos semânticos. Para Maingueneau (2008), é a exploração sistemática das possibilidades de um núcleo semântico o que possibilita aos enunciadores, à luz da competência discursiva, enunciarem de acordo com as restrições de uma formação discursiva dada.

Em relação ao diálogo com a obra do autor, algumas considerações devem ser feitas a partir da especificidade do corpus que focalizamos e do campo do Jornalismo. Em primeiro lugar, o mapeamento de traços semânticos constitutivos de enunciados jornalísticos a partir de diferentes planos discursivos sugere um cenário marcado não por identidades discursivas estabilizadas, mas por identidades abertas e arranjos semânticos deslizantes. Em outras palavras, é preciso considerar que estamos diante de mediações discursivas - mais do que de identidades semânticas bem delimitadas no espaço discursivo, como sugere a análise desenvolvida por Maingueneau (2008) a propósito do discurso religioso.

Assim, propomos que um processo de mediação discursiva desempenha papel fundamental à compreensão das formas de interação semântica e conformação de discursos no campo jornalístico. Para tanto, devemos pensar em termos de afinidades, trocas e negociações entre modelos semânticos, como mostra a coadunação verificada entre discursos corporativo-empresariais e discursos identitários de afirmação da diversidade, em sintonia com a crítica de Silvia Federici (2019) a respeito da limitação do potencial radical do feminismo no capitalismo; da negociação entre eles, resultam articulações discursivas propícias à valorização de narrativas de "empoderamento individual". Trata-se, no limite, de manifestações 
alinhadas ao que Françoise Vergès (2020) descreve como "feminismo civilizatório", que incorpora os objetivos da missão civilizatória ocidental, oferecendo uma politica dos direitos das mulheres subordinada a interesses imperialistas e neoliberais.

Destaca-se, em relação aos achados apontados nesta pesquisa, o fato de tais regras de formação atuarem sobre a construção de matérias que visibilizam tanto vivências femininas quanto questões relacionadas à população LGBT, o que sugere que a abordagem de diversas diferenças classificadas sob uma ótica de gênero é determinada, atualmente, por uma mesma formação discursiva na cobertura da imprensa de referência.

Muitas questões, obviamente, são deixadas da fora dos jornais: questões que emergem com os feminismos do século XXI, como aquelas em torno das multidões queer e da desidentificação, além das perspectivas decolonial e interseccional - por exemplo -, mostram-se ausentes da cobertura. No que parece uma expressão de um "feminismo difuso", expressão cunhada por Céli Regina Jardim Pinto (2003) há mais de uma década, a visibilização de mulheres e LGBTs nos jornais de referência não é feita desde um ponto de vista de gênero, embora passe por temas comuns na discussão teórica sobre gênero, diagnóstico similar àquele feito por Cláudia Lago, Mônica Martinez e Mara Coelho de Souza Lago (2016) a propósito da apropriação de referenciais dos estudos de gênero por pesquisas em Jornalismo no Brasil.

Ainda assim, é nas brechas abertas pela mediação entre modelos de restrição semântica que os jornais de referência parecem visibilizar, na contemporaneidade, minorias por muitos anos negligenciadas na cobertura da imprensa. Não obstante, a conquista desse espaço se dá - ainda hoje - nos termos de uma visibilidade negociada: a propósito dos temas e feições (negras, indigenas, mestiças, asiáticas, periféricas...) que se fazem ausentes do debate público re(a) presentado como espetáculo democrático, cabe lembrar das lições de Foucault (2008; 2012), já que a formação discursiva atua rarefazendo o dizer e o dito mais do que multiplicando as possibilidades de expressão.

\section{Referências}

BARBOSA, Mariana. Mulher empreendedora inova e retém mais talentos. Folha de S.Paulo, São Paulo, ano 91, n. 29.924, p. B3, 8 mar. 2011

BUTLER, Judith. Corpos que pesam: sobre os limites discursivos do 'sexo'. In: LOURO, Guacira L. O corpo educado: pedagogias da sexualidade. 2. ed. Belo Horizonte: Autêntica, 2001. p. 153-172.

BUTLER, Judith. Problemas de Gênero: feminismo e subversão da identidade. 2. ed. Rio de janeiro: Civilização Brasileira, 2008.

FEDERICI, Silvia. O ponto zero da revolução: trabalho doméstico, reprodução e luta feminista. São Paulo: Elefante, 2019.

FLECK, Isabel. As lobas de Wall Street. Folha de S.Paulo, São Paulo, ano 94, n. 31.020, p. B6, 8 mar. 2014.

FOUCAULT, Michel. A arqueologia do saber. Rio de Janeiro: Forense Universitária, 2012.

FOUCAULT, Michel. A ordem do discurso. São Paulo: Loyola, 2008.

FRASER, Nancy. Da redistribuição ao reconhecimento? Dilemas da justiça numa era pós-socialista. Tradução de Julio Assis Simões. Cadernos de Campo, São Paulo, v. 15, n. 14/15, p. 231-239, 2006. Disponivel em: http:// www.revistas.usp.br/cadernosdecampo/article/viewFile/50109/54229. Acesso em: 28 jul. 2020.

HALL, Stuart. A identidade cultural na pós-modernidade. Rio de Janeiro: DP\&A, 2019.

HALL, Stuart. A centralidade da cultura: notas sobre as revoluções culturais do nosso tempo. Tradução de Ricardo Uebel, Maria Isabel Bujes e Marisa Vorraber Costa. Educação \& Realidade, Porto Alegre, v. 22, n. 2, p. 15-46, jul./dez.1997. Disponivel em: http://www. seer.ufrgs.br/educacaoerealidade/article/view/71361. Acesso em: 28 jul. 2020.

HARAWAY, Donna. Manifesto Ciborgue: Ciência, tecnologia e feminismo-socialista no final do século $X X$. In: TADEU, T. (org.). Antropologia do ciborgue: as vertigens do pós-humano. Belo Horizonte: Autêntica, 2009. p. 33-118.

HOLLANDA, Helóisa Buarque. Introdução. In: HOLLANDA, Heloisa Buarque de (org.). Pensamento feminista: conceitos fundamentais. Rio de Janeiro: Bazar do Tempo, 2019. p. 9-21.

KLINGER, Karina. Respeito à diversidade aprende-se na infância. Folha de S.Paulo, São Paulo, ano 81, n. 26.374, 18 jun. 2001. Equilibrio.

LAGO, Cláudia; MARTINEZ, Mônica; LAGO, Mara Coelho de Souza. Estudos de gênero na pesquisa em jornalismo no Brasil: uma tênue relação. Revista Famecos, Porto Alegre, v. 23, n. 2, p. 1-23, maio/ago. 2016. Disponivel em: https://revistaseletronicas.pucrs.br/ojs/ index.php/revistafamecos/article/view/22464. Acesso em: 30 ago. 2020. 
LAURETIS, Teresa de. A tecnologia de gênero. In: HOLLANDA, Heloisa Buarque de (org.). Pensamento feminista: conceitos fundamentais. Rio de Janeiro: Bazar do Tempo, 2019. p. 121-155

LUCENA, Eleonora de. Quero "empoderar" mulheres de baixa renda. Folha de S.Paulo, São Paulo, ano 91, n. 29.924, p. C9, 8 mar. 2011.

MAINGUENEAU, Dominique. Gênese dos Discursos Curitiba: Criar Edições, 2008.

MAINGUENEAU, Dominique. Doze conceitos em análise do discurso. Tradução de Adail Sobral et al. São Paulo: Parábola Editorial, 2010.

MATOS, Marlise. Teorias de gênero ou teorias e gênero? Se e como os estudos de gênero e feministas se transformaram em um campo novo para as ciências. Estudos Feministas, Florianópolis, v. 16, n. 2, p. 333-358, 2008. Disponivel em: http://www.scielo.br/scielo.php? scrip$\mathrm{t}=\mathrm{sci}$ _arttext\&pid=S0104-026X2008000200003 . Acesso em: 30 ago. 2020.

NORRIS, Pippa; INGLEHART, Ronald. Cultural Backlash: Trump, Brexit and authoritarian populism. Cambridge: Cambridge University Press, 2019.

ORTIZ, Renato. Universalismo e diversidade: contradições da modernidade-mundo. São Paulo: Boitempo, 2015.

PALHARES, Isabela; DIÓGENES, Juliana. O desafio de quem quer definir seu próprio destino. $\mathbf{O}$ Estado de $\mathbf{S}$. Paulo, São Paulo, ano 139, n. 45.432, p. A17, 8 mar. 2018.

PALHARES, Isabela; DIÓGENES, Juliana. Como vivem as brasileiras pelo mundo. O Estado de S. Paulo, São Paulo, ano 138, n. 45.067, p. A14, 8 mar. 2017.

PINTO, Céli Regina Jardim. Uma história do feminismo no Brasil. São Paulo: Perseu Abramo, 2003.

RIBEIRO, Cristina; MENOCCHI, Simone. Jeito feminino, o segredo do sucesso. O Estado de S. Paulo, São Paulo, ano 125, n. 40.319, p. A7, 8 mar. 2004.

SCABIN, Nara Lya Cabral. Mediação como gênese: Uma análise da conformação de discursos midiáticos identitários a partir do debate sobre gênero em O Estado de S. Paulo, O Globo e Folha de S.Paulo entre 1978 e 2018. 2020. Tese (Doutorado em Ciências da Comunicação) - Universidade de São Paulo, São Paulo, 2020.

SCOTT, Joan. Gênero: uma categoria útil para análise histórica. In: HOLLANDA, Heloisa Buarque de (org.). Pensamento feminista: conceitos fundamentais. Rio de Janeiro: Bazar do Tempo, 2019. p. 49-80.

SOUTO, Luiza. Estudantes com identidade. O Globo Rio de Janeiro, ano 93, n. 30.687, p. 43, 13 ago. 2017

VERGĖS, Françoise. Um feminismo decolonial. São Paulo: Ubu editora, 2020.

WIZIACK, Julio; ROLLI, Claudia. Abrindo portas. Folha de S.Paulo, São Paulo, ano 89, n. 29.285, p. B6, 7 jun. 2009.

WOODWARD, Kathryn. Identidade e diferença: uma introdução teórica e conceitual. In: SILVA, Tomaz Tadeu (org.) WOODWARD, Kathryn; HALL, Stuart. Identidade e diferença. Petrópolis: Vozes, 2014. p. 7-72.
ZAMIN, Angela. Jornalismo de referência: o conceito por trás da expressão. Revista Famecos, Porto Alegre, v. 2, n. 3, p. 918-942, set./dez. 2014. Disponivel em: https://www.redalyc.org/pdf/4955/495551017008.pdf. Acesso em: 4 jul. 2020.

\section{Nara Lya Cabral Scabin}

Doutora em Ciências da Comunicação pela Universidade de São Paulo (USP), em São Paulo, SP, Brasil; professora do Programa de Pós-graduação em Comunicação da Universidade Anhembi Morumbi (UAM), em São Paulo, SP, Brasil.

\section{Endereço para correspondência}

Nara Lya Cabral Scabin

Universidade Anhembi Morumbi

Rua Casa do Ator, 294

Unidade $5-7^{\circ}$ andar - Campus Vila Olimpia

Vila Olimpia, 04546-001

São Paulo, SP, Brasil

Os textos deste artigo foram revisados pela Poá Comunicação e submetidos para validação da autora antes da publicação. 